\title{
Prediction of thickness distribution of thermoformed multilayer ABS/PMMA sheets
}

Caroline Jobey, Nadine Allanic, Pierre Mousseau, and Rémi Deterre

Citation: AIP Conference Proceedings 1769, 170033 (2016); doi: 10.1063/1.4963589

View online: https://doi.org/10.1063/1.4963589

View Table of Contents: http://aip.scitation.org/toc/apc/1769/1

Published by the American Institute of Physics

\section{Articles you may be interested in}

Testing single point incremental forming molds for thermoforming operations

AIP Conference Proceedings 1769, 060016 (2016); 10.1063/1.4963452

Movement of patches during thermoforming: Experiment and simulation

AIP Conference Proceedings 1769, 170032 (2016); 10.1063/1.4963588

Consolidation modelling for thermoplastic composites forming simulation

AIP Conference Proceedings 1769, 170044 (2016); 10.1063/1.4963600

Automotive view on forming of continuous fiber reinforced composites and its simulation

AIP Conference Proceedings 1769, 170031 (2016); 10.1063/1.4963587

Material characterization for thermoforming-simulation

AIP Conference Proceedings 1779, 050002 (2016); 10.1063/1.4965507

A Study of Stress Relaxation with Finite Strain

Transactions of the Society of Rheology 7, 391 (1963); 10.1122/1.548963 


\title{
Prediction of thickness distribution of thermoformed multilayer ABS/PMMA sheets
}

\author{
Caroline Jobey ${ }^{\text {a) }}$, Nadine Allanic, Pierre Mousseau, Rémi Deterre \\ LUNAM Université, Université-IUT de Nantes, CNRS, GEPEA, UMR 6144, France.. \\ ${ }^{a)}$ Corresponding author: caroline.jobey@univ-nantes.fr
}

\begin{abstract}
In thermoforming, one of the main difficulties is to avoid the presence of weak thickness in the most deformed zones. After the heating stage, a bubbling step, leading to a first rate of deformation, is often used. In this work, we assess how the initial bubbling deformation can be controlled in order to obtain a homogeneous final thickness of the product. Experiments are performed on a multilayer sheet product. An industrial mould, corresponding to a casing of a nonlicensed car, was adapted on a lab thermoformer. After presenting experimental thermal profiles of the multilayer sheets measured during the heating stage, a first geometric model is investigated to predict the thickness distribution. Numerical results are compared with measurements.
\end{abstract}

\section{INTRODUCTION}

Thermoforming is a moulding process extensively used for the production of polymer parts with thin-walls and relatively simple geometries. Due to the low cost of the tools and the short development times, the standard thermoforming process tends to be extended to technical parts with large dimensions in many industrial areas (yachting, sanitary, automobile,...) [1]. This extension needs to adapt thermoforming to thick sheets $(>2 \mathrm{~mm})$ to product parts with complex geometries involving high deformation rate [2,3]. One of the main difficulties relies in the control of the final thickness distribution [4]. For this purpose, the introduction of a step of bubbling, enabling a pre-stretching of the material, is a classical way to enhance the result in industrial processes. The initial temperature of the sheet influences the height of the bubble and thus the thickness distribution [5].

In this study, geometric considerations are formulated in order to express the relation between the bubbling thickness distribution and the distribution in the final part. Modelling predictions are confronted to experimental results obtained with the use of an industrial mould and a lab thermoformer, specifically thermally controlled. Based on thermal measurements during the heating stage, a proposal is made to show how the bubble's shape can be adapted to the mould in order to improve the thickness distribution of the part.

\section{MATERIAL AND METHODS}

The domain of application concerned by this study is the production of non-licensed cars. Many pieces of the car body, having complex geometries, are simultaneously thermoformed with a positive mould. Multilayer sheets of ABS/PMMA obtained by coextrusion are used so that both the specific qualities of each material can be used: high mechanical properties of ABS, brilliance and UV resistance of PMMA. Analyses are performed in lab conditions representative of the industrial conditions described in this section.

\section{Characterization of Multilayer ABS/PMMA Sheets properties}

To avoid an early deterioration of the product, a minimal thickness of $1.1 \mathrm{~mm}$ after thermoforming is required. Thus, according to the geometry of the produced parts and the involved deformation rate, the initial thickness of the sheet 
can vary from 2.5 to $3 \mathrm{~mm}$ sheet with five layers of ABS/PMMA. A microscopic observation of a $2.5 \mathrm{~mm}$ sheet is shown Figure 1a. It shows that it is constituted of two layers of PMMA corresponding to a PMMA clear layer (205 $\mu \mathrm{m})$ and a PMMA colored layer $(370 \mu \mathrm{m})$. ABS area is constituted of three layers, respectively corresponding to an ABS color layer $(656 \mu \mathrm{m})$, an ABS (regrind) carrier layer $(902 \mu \mathrm{m})$ and an ABS virgin $(370 \mu \mathrm{m})$. In first approximation, the material was considered as homogeneous. The $\alpha$-transition [6] temperature of $123^{\circ} \mathrm{C}$ was deducted from DMTA analysis in the linear visco-elastic region, using tensile measurements at $1 \mathrm{~Hz}$ and an imposed deformation of 0.0035 (Figure 1b). Samples were studied both in parallel and perpendicular to the direction of extrusion. It was observed no anisotropic effects in these experiments. Figure $1 \mathrm{~b}$ shows an important decrease of the elastic modulus after $\alpha$-transition, from $19 \mathrm{MPa}\left(123^{\circ} \mathrm{C}\right)$ to $0,28 \mathrm{MPa}\left(189^{\circ} \mathrm{C}\right)$. This thermal range is the rubber sheet and corresponds to the thermoforming range [6]. It is relatively large, which is explained by the high molar mass of the polymer.

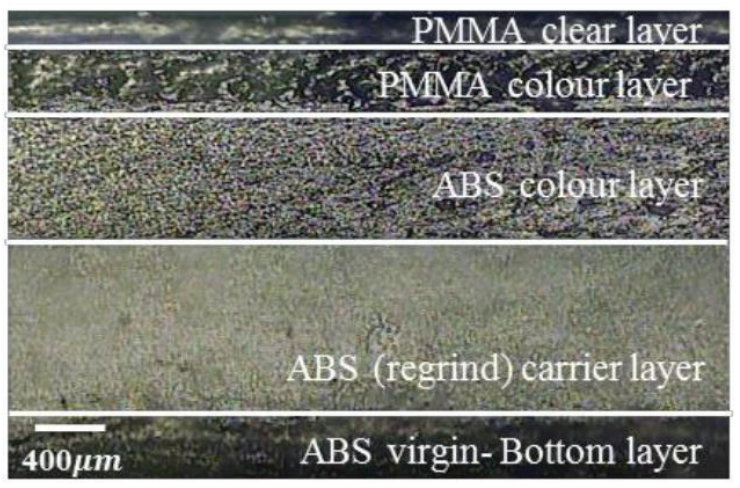

(a)

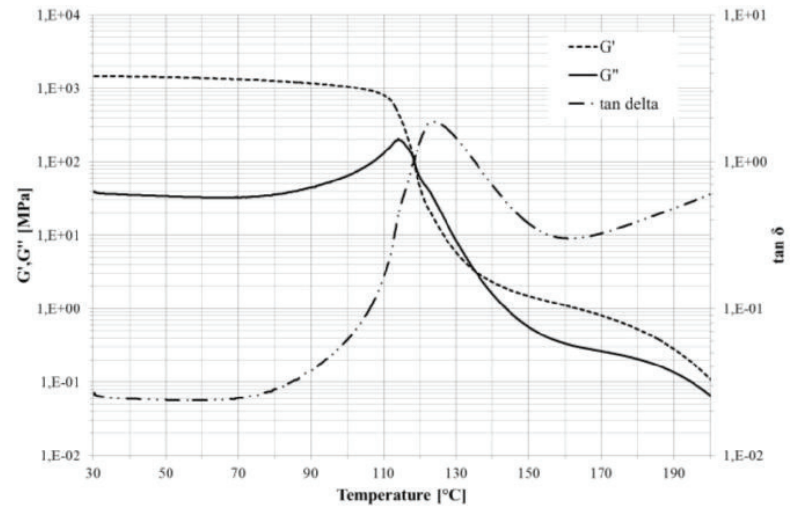

(b)

FIGURE 1. Multilayer ABS/PMMA sheets

(a) composition observed with an optical microscope (b) Mechanical properties

\section{Thermoforming Process}

A lab thermoformer (FORMECH 508FS) was investigated and schemed in Figure 3. It is equipped with a bubbling system, a vacuum pump for the forming process and a fan for the cooling stage. The maximal allowed size of the sheet is $508 \times 457 \mathrm{~mm}^{2}$, corresponding to a forming zone of $482 \times 432 \mathrm{~mm}^{2}$. The radiative heating represented in Figure 3a is located on the upper side of the sheet. It is constituted of 15 quartz infrared emitters, divided into four independent regulated zones. The maximal infrared radiations depend on the area, and evolve from 9.8 to 19.4 $\mathrm{kW} \cdot \mathrm{m}^{-2}$ (indicated on Figure 3a). The mould can be regulated by a water system associated to a thermoregulation system.

During the process, the sheet is first heated until its softening temperature, then bubbled to be early deformed. The forming of the material is induced by the vertical movement of the mould and the beginning of aspiration (Figure 2). The part is cooled by conduction with the mould and by forced convection. 


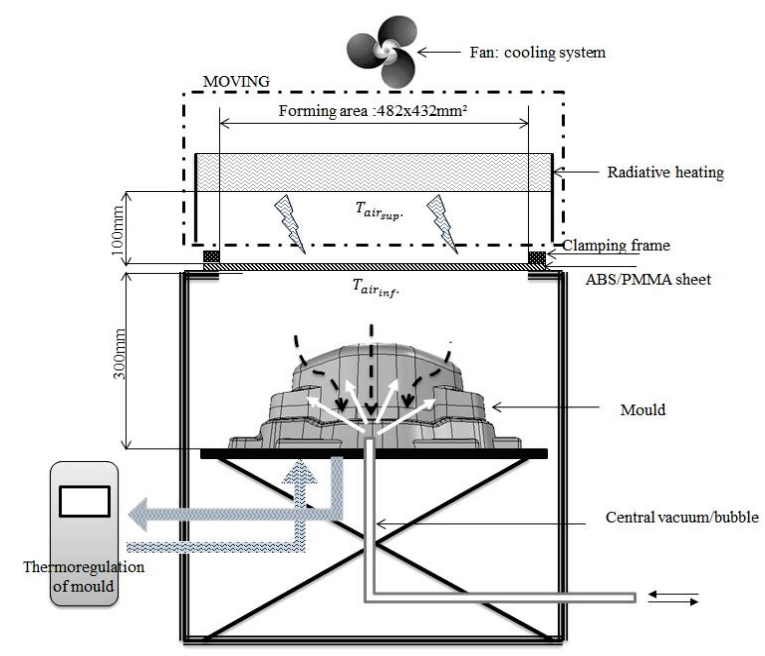

FIGURE 2. Global view of the thermoformer

(a)

\begin{tabular}{|c|c|c|}
\hline \multicolumn{3}{|c|}{$\begin{array}{c}\text { Area } 3 \\
\Phi_{\max }=16.2 \mathrm{~kW} / \mathrm{m}^{2}\end{array}$} \\
\hline $\begin{array}{c}\Phi_{\max }= \\
16.2 \mathrm{~kW} / \mathrm{m}^{2} \\
\text { Area 2 } \\
\Phi_{\max }= \\
9.8 \mathrm{~kW} / \mathrm{m}^{2}\end{array}$ & $\begin{array}{c}\text { Area 1 } \\
\Phi_{\max }=13 \mathrm{~kW} / \mathrm{m}^{2}\end{array}$ & $\begin{array}{c}\Phi_{\max }= \\
16.2 \mathrm{~kW} / \mathrm{m}^{2} \\
\text { Area 2 } \\
\Phi_{\max }= \\
9.8 \mathrm{~kW} / \mathrm{m}^{2}\end{array}$ \\
\hline & $\begin{array}{c}\Phi_{\max }=19.4 \mathrm{~kW} / \mathrm{m}^{2} \\
\text { Area } 4\end{array}$ & \\
\hline
\end{tabular}

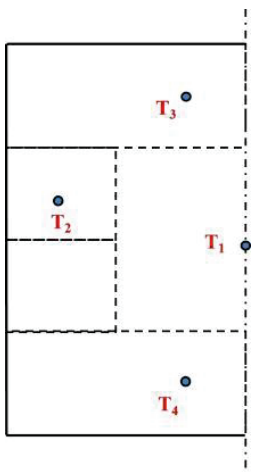

(b)

FIGURE 3. Experimental configuration

(a) infrared heating (b) thermocouples position

A mould of a piece of carter, represented on Figure 4, was chosen for this study. It is not axisymmetric, and its variation of geometries involves a large range of deformation rate. For the experiments, the considered ABS/PMMA sheet has a $500 \mathrm{~mm}$ width, $450 \mathrm{~mm}$ length and $2.5 \mathrm{~mm}$ thickness. The infrared radiations were respectively imposed to $70 \%$ of the maximal value in area 1 , and $80 \%$ in the others. The mould is regulated to $75^{\circ} \mathrm{C}$, same as in the industrial process. Before thermoforming part, the sheet was squared (tile of $50 \times 50 \mathrm{~mm}^{2}$ ) in order to observe stress ratio as shown in Figure 4b.

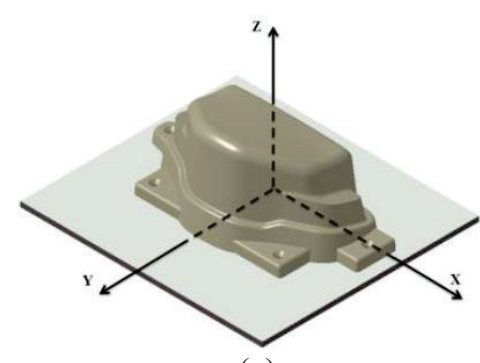

(a)

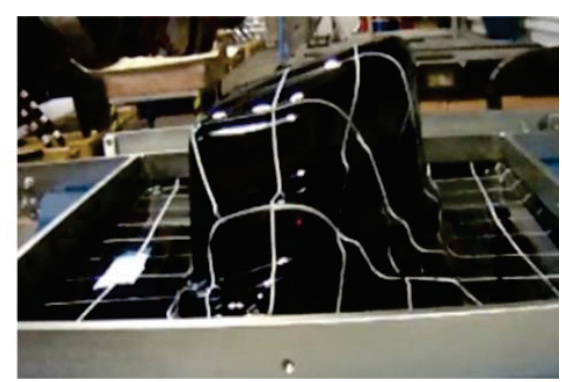

(b)

FIGURE 4. a) Global view of the carter piece mould and b) thermoformed part 


\section{Modelling}

To define the geometrical profile of the bubble, we use an analysis structural of the thermoplastic plate under constraint with CATIA. We used a linear elastic model. The maximal amplitude of the displacement corresponds to experimental observation and is fixed to $140 \mathrm{~mm}\left(\mathrm{z}_{\max }\right.$ indicated on Figure 5). We apply a constraint of connection, of standard embedding, all around the thermoplastic plate (corresponding to the clamping frame).

The method consists in model the thickness distribution of the part on the mold by a geometrical approach. A conservation of volume is assumed corresponding to a Poisson's ratio of about 0.5 , which is coherent for rubber like material. In a first time, the bubble thickness is determined by projection of the sheet surface $\left(\mathrm{S}_{\mathrm{p}}\right)$ on the bubble surface $\left(\mathrm{S}_{\mathrm{b}}\right)$. The geometry of the bubble is replaced by the equivalent spherical cap with a radius of curvature of $500 \mathrm{~mm}$. The center of the spherical cap is used to determine the successive solid angles $\left(\alpha_{1}, \alpha_{2}, \ldots\right)$.

In each solid angle, we realize a projection of sections of the spherical cap corresponding to the section of the bubble and section of the sheet. The projection of each surface $\left(\mathrm{S}_{\mathrm{p}} / \mathrm{S}_{\mathrm{b}}\right)$ determines the local strain rate, and thus, by multiplying by initial thickness $\left(\mathrm{e}_{0}\right)$, determines the local averaging thickness of bubble $\left(\mathrm{e}_{\mathrm{b}}\right)$ related to the corresponding angular area. In order to calculate the thickness of the part, we project the surface of the spherical cap on the surface of the mold, related to the solid angles. By multiplying this surface ratio by the thickness of the bubble, we determine the local average thickness of the thermoforming product.

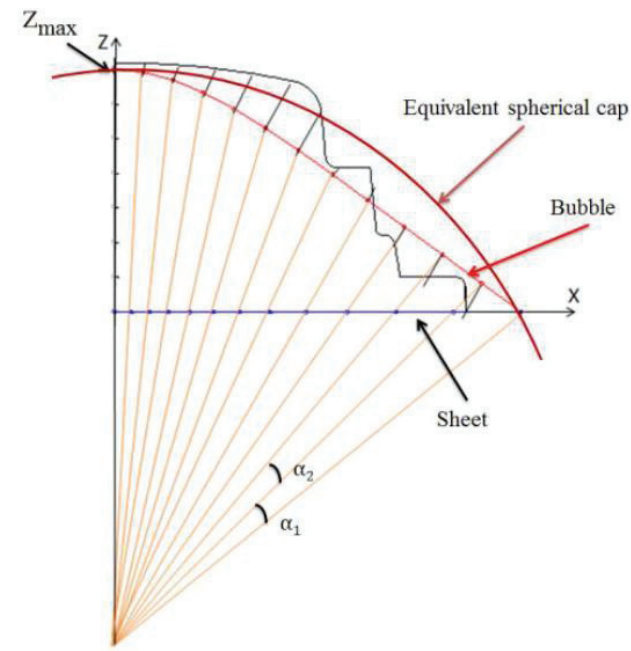

a)

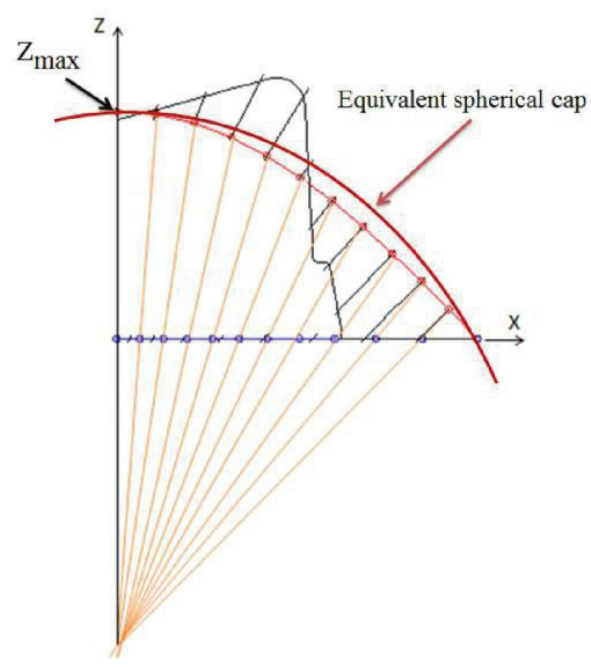

b)

FIGURE 5. Explicit schema to predict a thickness distribution of bubble and part thermoforming, a) in plan XZ and b) in plan YZ

\section{RESULTS AND DISCUSSION}

\section{Thermal profiles of temperatures during the heating stage}

A preliminary test was performed to analyse the thermal behaviour of the material during the heating stage. To do so, a $2.9 \mathrm{~mm}$ thick sheet was instrumented with ten $1 \mathrm{~mm}$ thermocouples of type K. Placed at the surface of each side of the sheet, their positions are given in Figure 3b. The air temperature is also measured at the midway between the sheet and the heater bank at the upper and lower side of the sheet. The results obtained during a 300 seconds heating time are given in Figure 6a for the upper side and Figure 6c for the lower side. After this time, every temperature is higher than the glass temperature. Figure $6 \mathrm{~b}$ shows the gap of temperature between each side of the sheet at the end of heating. It varies from $22 \mathrm{~K}$ to $28 \mathrm{~K}$. This result is coherent with the presence of only one heating bank and the increase of the oven air temperature. It reaches $110^{\circ} \mathrm{C}$ at the upper side and twice less at the lower side. 


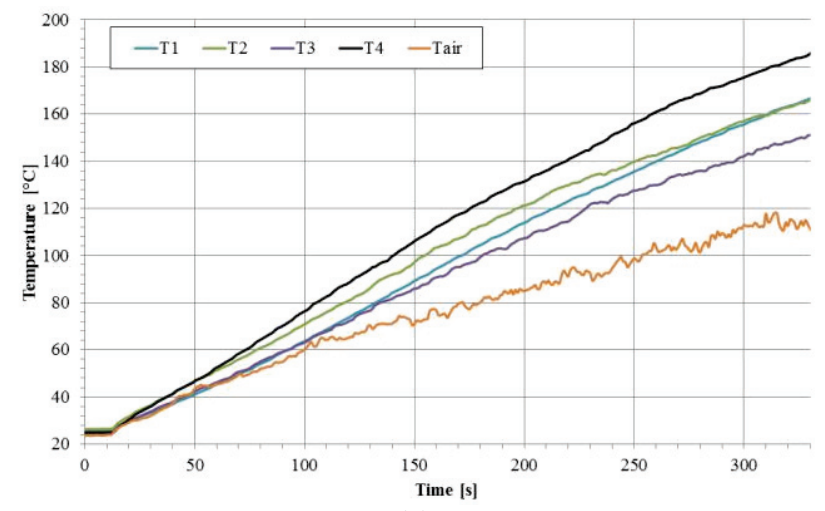

(a)

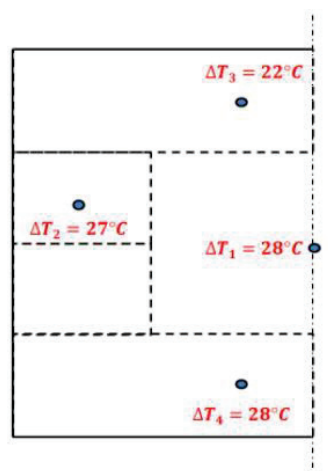

(b)

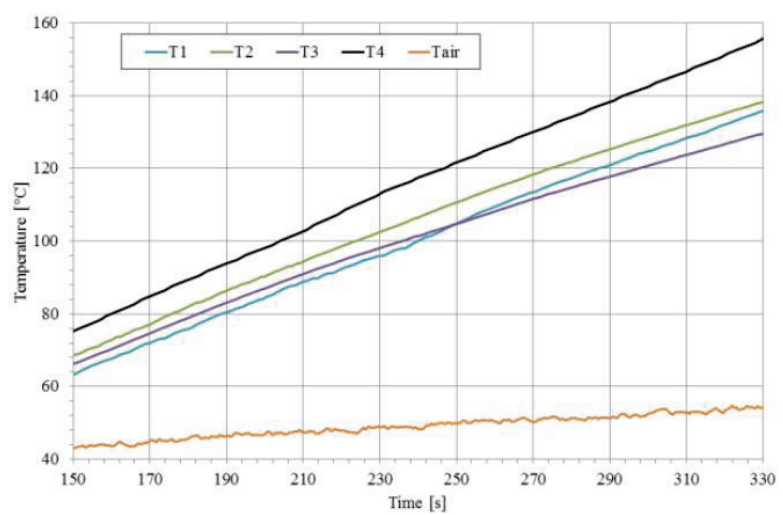

(c)

FIGURE 6. Temperature profiles of the sheet during the heating stage: a) upper layer, b) lower layer and c) temperature gradient

This experiment shows that, according to experimental configuration, the sheet can undergo high temperature in thickness but also in the other directions due to the non-uniform infrared radiation. In this experimental configuration, the temperature of the sheet varies from $135^{\circ} \mathrm{C}$ to $190^{\circ} \mathrm{C}$ at the surface of PMMA. The Figure $1 \mathrm{~b}$ shows that the multilayer sheets elastic modulus highly decreases with temperature. Thus, during the steps of bubbling and forming, the deformation of ABS/PMMA is heterogeneous. The presence of a high gradient of temperature encourages the appearance of high strains inside the material and fixes the bubbling conformation [7].

One of the possibilities of control thickness of the part is to optimize the shape of the bubble according to the temperature of plate, and thus to balance the variations thickness in the thermoforming part.

\section{Thickness distribution of the thermoformed sheet}

Figure 7 shows the comparison of thickness distribution in the part between the experimental data and the predicted results for a $2.5 \mathrm{~mm}$ sheet. The thickness profiles are given in two directions, along the planes XZ (symmetric plan) and YZ, as seen in Figure 4a. Thickness was measured using an Ultrasonic Thickness Gauge. Figure 7 shows also the considered bubble thickness distribution. The deformation rate is higher at the top of the bubble and the obtained thickness profile is coherent with literature [8,9]. By considering an initial constant thickness of the bubble, the gap between experimental and numerical results for the part is irregular and not negligible. By considering this prestretching of the bubble, the numerical results of the thickness profile of the part are close to the experimental ones. The profile is correct, even if only geometrical considerations are taken into account. Thus, the bubbling stage modelling is essential to describe the product final thickness well. The simulated and measured thicknesses remain in the tolerance range of thicknesses $(>1.1 \mathrm{~mm})$ except in one located zone (in plan YZ). This most sensitive zone corresponds to the high variation of height of the part and is situated in the Area 3 . The measured temperature in this area (Figure 5) is lower than the others. An increasing of temperature at proximity of this zone could be helped to equilibrate deformation. 

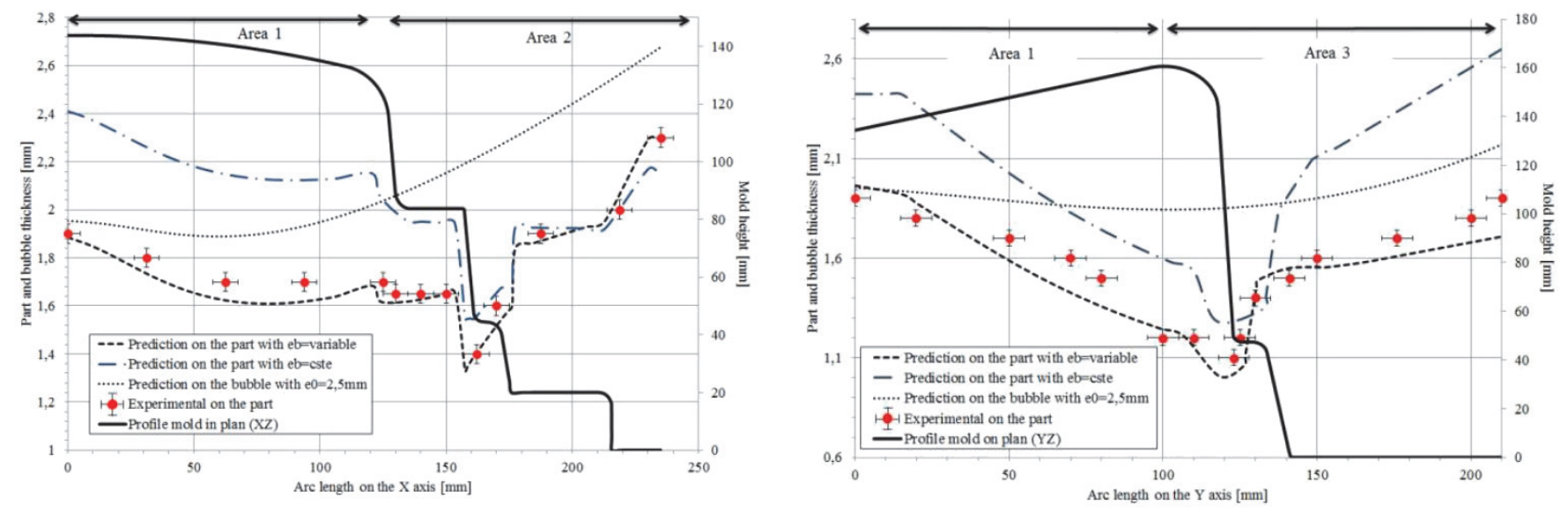

FIGURE 7. Thickness distribution of the thermoformed sheet on the $\mathrm{X}$ axis a) and $\mathrm{Y}$ axis b)

\section{CONCLUSION}

The influence of bubbling step in the performance of thermoforming was studied. Experimental investigation was performed on a multilayer ABS/PMMA sheet. The thickness distribution was predicted, by taking into account surface ratio. The good agreement of the model with experimental results was obtained with a non-trivial geometry of mould. In the following, the hyper-elastic behaviour of the material should be taken into account in order to improve the modelling before using inverse method to predict the optimal configuration.

\section{REFERENCES}

1. Ashter, Syed Ali. «1 - Introduction to Thermoforming ». In Thermoforming of Single and Multilayer Laminates, édité par Syed Ali Ashter, 1-12. Oxford: William Andrew Publishing, 2014.

2. aus der Wiesche, Stefan. "Industrial Thermoforming Simulation of Automotive Fuel Tanks ». Applied Thermal Engineering 24, $\mathrm{n}^{\mathrm{O}} 16$ (novembre 2004): 2391-2409. doi:10.1016/j.applthermaleng.2004.03.003.

3. H. Metwally, and P.Ding, "Implementing simulation driven product development for thermoforming of an instrument panel", ANSYS, 2012.

4. Erdogan, Ertugrul Selcuk, et Olcay Eksi. "Prediction of Wall Thickness Distribution in Simple Thermoforming Moulds ». Strojniški vestnik - Journal of Mechanical Engineering 60, $\mathrm{n}^{\mathrm{o}} 3$ (15 mars 2014): 195-202. doi:10.5545/sv-jme.2013.1486.

5. Lee, Je Kyun, Terry L. Virkler, et Chris E. Scott. "Influence of initial sheet temperature on ABS thermoforming ». Polymer Engineering \& Science 41, n ${ }^{\circ} 10$ (2001): 1830-44.

6. Billon, N. "Constitutive Model for HIPS in the Thermoforming Range ». International Journal of Material Forming 1, $\mathrm{n}^{\mathrm{O}} \mathrm{S} 1$ (avril 2008): 679-82. doi:10.1007/s12289-008-0306-7.

7. Nam, Gi Joon, Jae Wook Lee, et Kyung Hyun Ahn. « Three-dimensional simulation of thermoforming process and its comparison with experiments ». Polymer Engineering \& Science 40, $\mathrm{n}^{\circ} 10$ (2000): 2232-40.

8. Dong, Y., R. J. T. Lin, et D. Bhattacharyya. « Determination of critical material parameters for numerical simulation of acrylic sheet forming ». Journal of materials science 40, ${ }^{0} 2$ (2005): 399-410.

9. Rachik, M., F. Schmidt, N. Reuge, Y. Le Maoult, et F. Abbeé. « Elastomer biaxial characterization using bubble inflation technique. II: Numerical investigation of some constitutive models ». Polymer Engineering \& Science $41, \mathrm{n}^{\mathrm{O}} 3$ (2001): 532-41. 